\title{
Degenerated small bioprostheses: Still a challenge
}

\author{
Manuel J. Antunes, MD, PhD, DSc
}

\footnotetext{
From the Center of Cardiothoracic Surgery, University Hospital and Faculty of Medicine, University of Coimbra, Coimbra, Portugal.

Disclosures: Author has nothing to disclose with regard to commercial support

Received for publication Aug 12, 2017; accepted for publication Aug 19, 2017; available ahead of print Sept 19, 2017.

Address for reprints: Manuel J. Antunes, MD, PhD, DSc, Centro de Cirurgia Cardiotorácica, Centro Hospitalar Universitário de Coimbra, Praceta Professor Mota-Pinto, 3000-075 Coimbra, Portugal (E-mail: antunes.cct. chuc@sapo.pt).

J Thorac Cardiovasc Surg 2018;155:70-1

$0022-5223 / \$ 36.00$

Copyright $(\underset{0}{ } 2017$ by The American Association for Thoracic Surgery

http://dx.doi.org/10.1016/j.jtcvs.2017.08.067
}

Degeneration of bioprostheses is an increasingly common occurrence. Classically, it required reoperation for valve rereplacement. Recently, however, percutaneous valve-invalve implantation has completely changed the picture, especially for elderly patients. ${ }^{1}$ In selected cases, this procedure can be performed with relatively low mortality and morbidity, although reoperation can now also be done with lower risk than that reported in the past.

Reoperations are technically more demanding than the correspondent primary procedures, and removal of dysfunctional prostheses is the principal factor of risk because of potential injury to neighboring structures, especially the mitral valve in the case of aortic valve re-replacements and the aortic valve in the case of mitral valve procedures. ${ }^{2}$ Different technical modifications have therefore been described with the intent of facilitating the procedure.

This editorial commentary pertains exclusively to failure of aortic bioprostheses. The valve-on-valve technique, introduced by Stessano and colleagues ${ }^{3}$ two and a half decades ago, consists of removal of the degenerated bioprosthetic leaflets and insertion of a mechanical valve (usually a size down) within the ring of the bioprosthesis. Because mechanical valves are generally hemodynamically more efficient than bioprostheses, this can be done without compromising the effective valve orifice in most cases; it is not appropriate, however, in the case of a previously implanted small prosthesis.

The percutaneous valve-in-valve procedure is also not free of limitations. First, it is also conditioned by the size of the failed prosthesis and the size of the currently available percutaneous devices. Second, and most important, it can only be done in specialized catheterization laboratories or surgical departments, which are still not available in every institution, region, or country. To these limitations one must add the considerable costs, variable from center to center, in most cases more expensive than surgery.

These were the dilemmas that Inoue and colleagues ${ }^{4}$ from Japan faced in their case described in this issue of

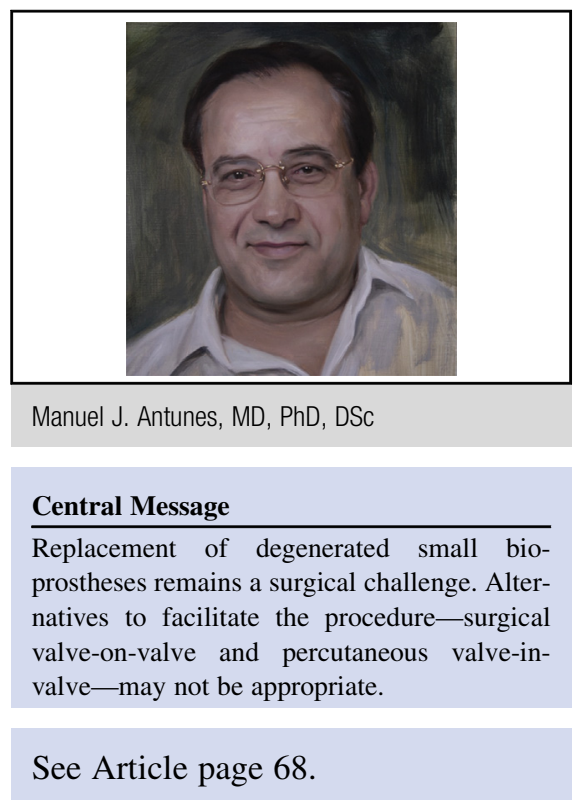

the Journal. Their patient was an 82-year-old woman who had undergone aortic valve replacement with a $19-\mathrm{mm}$ bovine bioprosthetic valve and Dacron polyester fabric patch augmentation of a small aortic annulus and sought treatment 15 years later with failure of the bioprosthesis. Because of severe adhesions and the heavily calcified Dacron polyester fabric patch, Inoue and colleagues ${ }^{4}$ determined that explantation of the old valve would have been "very hazardous." In addition, the bioprosthesis was too small for the valve-on-valve procedure, and there was no access to valve-in-valve procedures in their country at that time (2012).

Inoue and colleagues ${ }^{4}$ therefore used an innovative "chimney technique," consisting of removal of the degenerated bioprosthetic leaflets and implantation of a short-valved (16-mm mechanical valve) vascular prosthesis (18 $\mathrm{mm}$ in diameter) sewn to the ring of the bioprosthesis. The patient has since been followed up for 5 years and remains in New York Heart Association functional class I in sinus rhythm, with good left ventricular function (ejection fraction of $77 \%$ ) and low transvalvular pressure gradient (6.4 $\mathrm{mm} \mathrm{Hg}$ ).

Several questions can be raised. (1) Why did this article merit publication in the Journal? (2) Is it of significant interest to its readers? (3) Especially, is this a preferable technique to be used in a significant number of cases of bioprosthetic degeneration? The answer to this last question is certainly negative; in my opinion, however, this is an option that surgeons should keep in 
their armamentarium, ready at hand for use in the occasional situation such as that described by Inoue and colleagues. ${ }^{4}$

But there is another important message to be derived from this case report. The use of small bioprostheses should be avoided whenever possible, because they will be at high risk for classic "complete" replacement and will not be susceptible to treatment by either surgical valve-on-valve or percutaneous valve-in-valve procedures.

\section{References}

1. Webb JG, Mack MJ, White JM, Dvir D, Blanke P, Herrmann HC, et al Transcatheter aortic valve implantation within degenerated aortic surgical bioprostheses: PARTNER 2 Valve-in-Valve Registry. J Am Coll Cardiol. 2017; 69:2253-62.

2. Antunes MJ. Isolated replacement of a prosthesis or a bioprosthesis in the aortic valve position. Am J Cardiol. 1987;59:350-2

3. Stessano P, Losi MA, Golino A, Gagliardi C, Iorio D, Marzullo M, et al Bioprosthesis replacement with mechanical valve implantation on the bioprosthetic ring. Surgical and 2D echo considerations. Eur J Cardiothorac Surg. 1993; 7:507-10.

4. Inoue Y, Kotani S, Suzuki S. Chimney technique for aortic valve-on-valve replacement. J Thorac Cardiovasc Surg. 2018;155:68-9. 